\title{
Burden of disease associated with X-linked hypophosphataemia in adults: a systematic literature review
}

\author{
L. Seefried ${ }^{1} \cdot$ M. Smyth ${ }^{2} \cdot$ R. Keen ${ }^{3} \cdot$ P. Harvengt ${ }^{4}$ \\ Received: 3 March 2020 / Accepted: 8 July 2020 / Published online: 24 July 2020 \\ (C) The Author(s) 2020
}

\begin{abstract}
Summary This systematic review collated evidence on the burden of XLH in adults. Data captured highlight the substantial ongoing burden of XLH in adulthood and identified unmet needs. Greater awareness and understanding of the impact of XLH in adulthood are needed to improve care and outcomes in adults with XLH.

Introduction X-linked hypophosphataemia (XLH) is a rare metabolic bone disease characterized by renal phosphate wasting and musculoskeletal manifestations. Whilst the disease's impact in children is well documented, information on the effects of this progressive, debilitating condition on adults is lacking. This systematic review aimed to collate existing evidence on the burden of XLH in adulthood to identify unmet needs.

Methods MEDLINE, Embase and Cochrane Library databases and recent congress reports were searched on 19 February 2019 for English-language publications describing the medical, humanistic and socio-economic impact of XLH in adults ( $\geq 18$ years old). In addition, a structured Internet search was conducted.

Results Of the 2351 articles identified, 91 met the selection criteria along with 44 congress abstracts. Data show that adults with XLH experience a range of clinical manifestations, particularly skeletal deformities and (pseudo)fractures, along with pain, dental abnormalities and impaired physical function and mobility. XLH in adulthood impacts on quality of life and places limitations on daily activities. The level of healthcare resource utilization among adults with XLH is indicative of substantial socio-economic burden; further research is needed to quantitate the economic impact on the healthcare system, society and patients. Adults with XLH may not receive appropriate care and treatment; a possible explanation for this is a lack of awareness among healthcare professionals.

Conclusion XLH in adults is associated with considerable disease burden and unmet needs. Forthcoming studies and increased awareness of the impact of XLH in adulthood should help to improve management of XLH in adulthood and patient outcomes.
\end{abstract}

Keywords Familial hypophosphataemic rickets · Illness burden · Quality of life $\cdot$ Systematic review $\cdot$ Unmet needs $\cdot$ X-linked hypophosphataemia

Electronic supplementary material The online version of this article (https://doi.org/10.1007/s00198-020-05548-0) contains supplementary material, which is available to authorized users.

P. Harvengt

pol.harvengt@gmail.com

1 Orthopedic Institute, König-Ludwig Haus, University of Würzburg, Würzburg, Germany

2 Kyowa Kirin International, Galashiels, UK

3 Royal National Orthopaedic Hospital, Stanmore, UK

4 RVRH-XLH, French association of patients with XLH (a member of the International XLH Alliance), 20 rue Merlin de Thionville, Appt 120, 92150 Suresnes, France

\section{Introduction}

X-linked hypophosphataemia (XLH; OMIM: \#307800) is a rare, genetically determined metabolic bone disease [1]. It is characterized by renal phosphate wasting and altered mineral metabolism, which cause a diverse range of clinical manifestations including skeletal and dental abnormalities that first become apparent during early childhood [2,3]. XLH is caused by mutations in the phosphate-regulating gene with homologies to endopeptidases on the $\mathrm{X}$ chromosome (PHEX), which lead to elevated circulating concentrations of the phosphatonin fibroblast growth factor 23 (FGF23) [1,2]. Elevated FGF23 levels affect bone mineralization and skeletal development via several mechanisms [4]. These include chronic hypophosphataemia 
and inappropriate (low to low normal) levels of active vitamin D (1,25-dihydroxyvitamin D), as well as local, autocrine/ paracrine mechanisms that are not yet fully elucidated [4].

In children, XLH presents as a broad range of clinical manifestations including rickets and associated limb deformities, impaired growth, pain and dental abnormalities, which together result in reduced health-related quality of life (HRQoL) [3, $5,6]$. Focus in clinical practice is on the management of the disease during childhood, while the skeleton is still developing, with treatment aiming to improve growth and reduce skeletal deformities [2,3]. Until recently, standard treatment for children with XLH consisted of active vitamin D analogues (calcitriol or alfacalcidol) and multiple daily doses of phosphate until growth was complete $[2,3]$. Burosumab, a fully human monoclonal antibody against FGF23, is now approved conditionally in Europe for the treatment of XLH with radiographic evidence of bone disease in children 1 year of age and older and adolescents with growing skeletons [7]. $\mathrm{XLH}$ in adulthood has received less clinical attention; there is currently no consensus regarding the use of conventional supplementation therapy in adults, although treatment of symptomatic adults is recommended [8], and no diseasespecific treatments are approved for adults with XLH in Europe. However, burosumab is approved for both adult and paediatric use in several countries outside of Europe, including the USA, where it is indicated for the treatment of XLH in adults and children 6 months of age and older [9]. There is increasing recognition that XLH imposes a substantial clinical burden in adults $[6,10$, 11]. In addition, several large studies have confirmed reduced HRQoL in adults with XLH [12-14], but this evidence has not been compiled. There is a need to collate data on the burden of XLH during adulthood, including the social, psychological and financial challenges that adults with XLH experience, to support wider adoption of appropriate treatment beyond adolescence and to improve patient outcomes.

The aim of this systematic review was therefore to collate existing evidence on the humanistic and economic burden of $\mathrm{XLH}$ in adults to gain an understanding of the unmet needs associated with the disease in adulthood.

\section{Methods}

There were two parts to this analysis: a systematic review of the published medical literature and a structured Internet search to capture additional sources of evidence. Initial literature searches were broad in scope, owing to the expected low frequency of publications on XLH in adulthood. Search terms used were designed to capture all available information on XLH.

\section{Systematic literature review}

A systematic review of the literature was performed in accordance with the 2009 Preferred Reporting Items for Systematic Reviews and Meta-Analyses (PRISMA) guidelines [15]. All publications including data pertaining to the unmet needs of adults with XLH published in English before 19 February 2019 were included. Publications containing information on children and adults were included only if results were presented separately for adults. Case studies, cohort studies, crosssectional studies, randomized controlled trials and narrative review articles were included.

\section{Literature searches}

Searches of the following databases were performed using Ovid on 19 February 2019: Embase (covering publications from 1974 to the present), Ovid MEDLINE (covering publications from 1946 to the present) and the Cochrane Library, comprising the Cochrane Database of Systematic Reviews, the Database of Abstracts of Reviews of Effects, the Cochrane Central Register of Controlled Trials, the Cochrane Methodology Register, the National Health Service Economic Evaluation Database, the Health Technology Assessment database and the American College of Physicians Journal Club Archives. Abstracts from all conferences held in the previous 5 years (February 2014 to February 2019) available in the Northern Light Life Sciences Conference Abstracts database were searched manually. Search terms for the systematic review are presented in Supplementary Table S1.

\section{Selection of eligible publications}

Titles and abstracts of publications captured in the searches were screened by a reviewer for potential relevance to the topic of interest based on predefined eligibility criteria. Eligible publications were those containing information on the epidemiology and/or humanistic burden of XLH in adults ( $\geq 18$ years old), as well as those including evidence on the economic burden associated with XLH in adulthood. Uncertainties regarding relevance were resolved by a second reviewer after initial screening. Relevant publications for inclusion were then confirmed by reviewing the full text of all publications meeting the eligibility criteria at title/abstract screening.

\section{Data extraction}

Data from the full text of publications meeting the inclusion criteria were extracted into an Excel workbook. Information on publication type, study design, sample size, participant demographics (including, if available, country, sex, average 
age, age at occurrence of first XLH manifestation and at diagnosis of XLH and treatment information), history of clinical manifestations and procedures and use of pain medication was extracted. Data on the following were also captured: the impact of XLH on HRQoL, home life, work and education, history of use of assistive devices for disability, home modifications, economic burden of the disease, epidemiology, disease awareness and any other data considered by the reviewer to pertain to the unmet needs of adults with XLH. Publications that reported on the same study were grouped at this stage to avoid repetition in the reporting of results. Where both a journal article and congress abstract(s) were published on a specific study, only data from the article are presented. Where two congress abstracts reported data from different patient cohorts from the same study that had not been published as a journal article, both sets of data are presented, with the common source study noted. Aspects of XLH in adulthood reported in the research and case study publications were assessed to identify common themes.

\section{Assessment of evidence quality}

Non-clinical trial research studies (cohort and cross-sectional studies) were evaluated for quality of evidence using the Newcastle-Ottawa Scale (Supplementary Table S2) [16].

\section{Structured review of sources of evidence on the Internet}

The systematic review was augmented by a structured Internet search, which was conducted using Google on 8 March 2019. The search terms used in the structured Internet search are presented in Supplementary Table S3. Sources of information on the unmet needs of adults with XLH that were not included in the systematic review were identified from websites captured in the search by a single reviewer, with any uncertainties regarding relevance resolved by a second reviewer. Any data considered by the reviewer to be relevant to the topic of interest were extracted from these sources into an Excel workbook.

\section{Results}

The PRISMA diagram for the selection of eligible publications is shown in Fig. 1. Overall, 135 publications met the criteria for inclusion (91 journal articles and 44 conference abstracts). Among the 91 journal articles, there were 40 case study publications (which described a total of 56 adults with XLH), 32 research articles (including 17 cohort studies, 13 crosssectional studies and two clinical trials; reported sample sizes ranged from 2 to 134 adults with XLH) and 19 review articles. Quality of evidence from the non-clinical trial research studies was rated as good, satisfactory and poor for 6 [17-22], 14 [10,
$11,23-34]$ and 10 [35-44] studies, respectively. Of the 44 conference abstracts, 13 described case studies (which included 12 adults with XLH not described in the journal articles), 27 described research studies (reported sample sizes ranged from 5 to 195 adults with XLH) and four were reviews.

The research and case study publications identified in this systematic review predominantly reported on three aspects of XLH in adulthood: (1) XLH-related manifestations and procedures, (2) clinical management and awareness of XLH in adults and (3) impact of XLH on quality of life. The numbers of publications reporting on these aspects are shown in Fig. 2. Limited data on the epidemiology of XLH were reported [40, 45]. None of the publications specifically assessed the economic impact of XLH in adults on the healthcare system or society.

\section{XLH-related manifestations and procedures}

Most $(n=48 / 59)$ research publications described the clinical manifestations of XLH. Of these, 24 publications covering 20 distinct studies reported the percentage of participants who had experienced specific manifestations (Table 1). The clinical features of XLH in adults reported in these studies comprised musculoskeletal manifestations (such as limb abnormalities, short stature, osteoarthritis, osteomalacia, fractures, muscle weakness, enthesopathy, joint stiffness and spinal stenosis), dental problems, pain, ambulation difficulties (including impaired mobility and gait disturbance), renal complications, fatigue, hyperparathyroidism, loss of balance, hearing loss and tinnitus. Structured assessments of physical performance were not reported. Concerning the musculoskeletal burden of XLH in adults, one cohort study reported a high prevalence of pseudofractures $(45 \% ; n=10 / 22)$, as well as a high prevalence of early-onset osteoarthritis and enthesopathy in 55\% and $33 \%$ of patients younger than 30 years, respectively [36]. In patients 30-66 years of age, the prevalence of osteoarthritis and enthesopathy were as high as $80 \%$ and $100 \%$, respectively [36]. Pain was often documented in the studies; the proportion of participants experiencing pain (of any type) varied widely between the studies, ranging from 45 $(n=9 / 20)$ in a phase $1 / 2$ clinical trial [50] to $100 \%(n=17 / 17$; [38] $n=18 / 18$ ) [41] in a cohort study and an interview-based study. Hypertension was reported in one research publication; $27 \%(n=6 / 22)$ of adult patients in that retrospective chart review had a history of hypertension [27]. Few publications discussed differences in disease severity between men and women; however, a retrospective cross-sectional study in 52 adults with XLH rated as good quality found that women had fewer sites of enthesopathy and were less likely to have severe dental disease than men [20]. Available data consistently demonstrated stunted growth in both men and women (Table 1). Limited data were available on body constitution (weight, body mass index [BMI] and body fat percentage); however, 


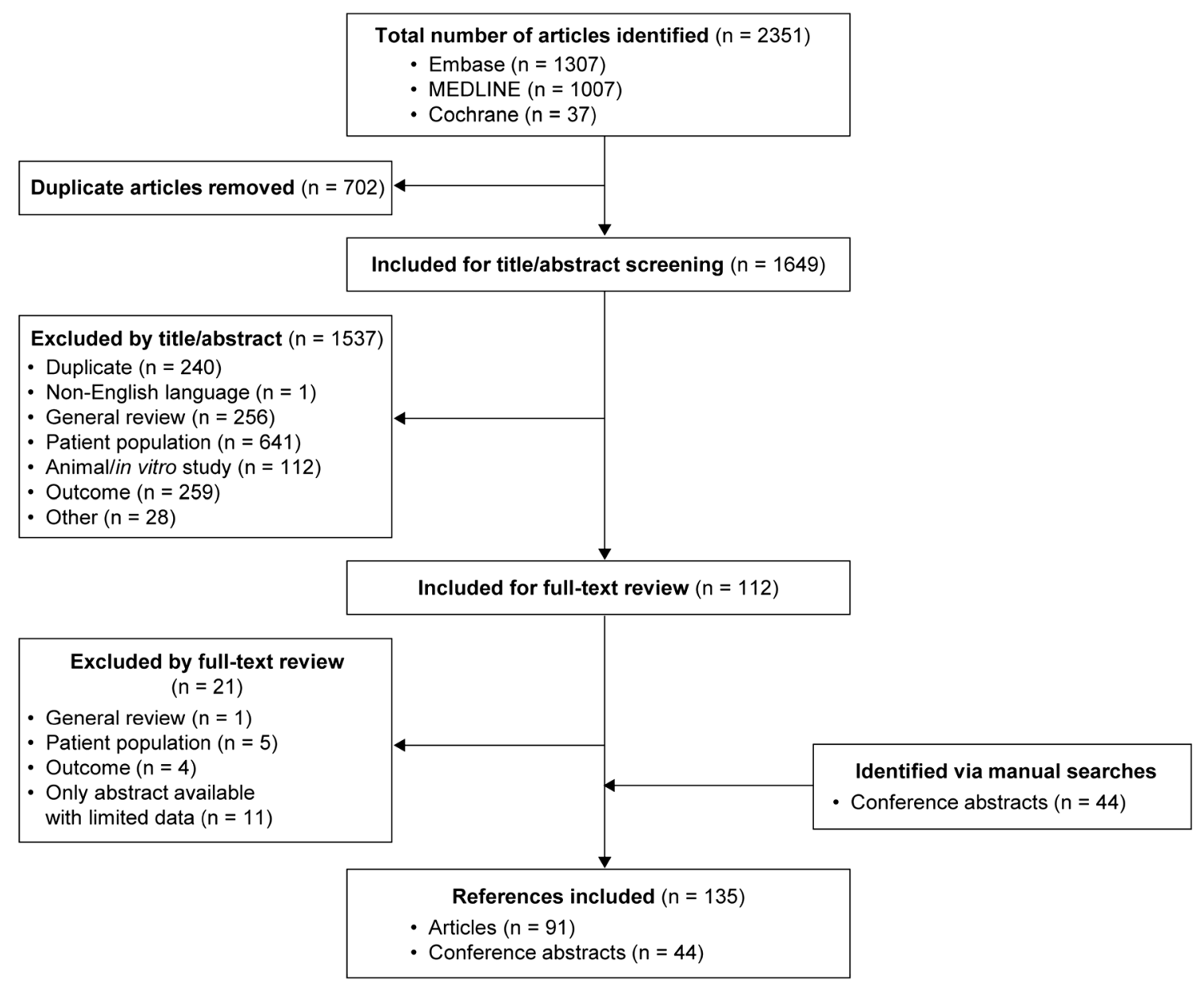

Fig. 1 PRISMA diagram of included and excluded references. PRISMA, Preferred Reporting Items for Systematic Reviews and Meta-Analyses

when reported, mean or median BMI was over $25 \mathrm{~kg} / \mathrm{m}^{2}$, suggesting a possible predisposition to adiposity and being overweight (Table 1) [18, 20, 34, 48].

Data on clinical manifestations in 68 adults with XLH were also reported in case study publications, which generally focused on specific manifestations or complications and did not provide comprehensive medical histories. The most frequently reported manifestations were limb deformity $(n=37)$, pain $(n=30)$, short stature $(n=30)$ and impaired mobility $(n=22$; Supplementary Fig. S1).

In the research studies with available data on surgical procedures, a high proportion of adults with XLH $(\geq 57 \%)$ reported a history of orthopaedic surgeries (Table 1). In a phase 3 clinical trial, a history of orthopaedic surgery was reported in $69 \%(n=92)$ of 134 patients ( $65 \%$ female), even though most of them $(81 \%)$ had received conventional supplementation therapy with phosphate and/or active vitamin D metabolites or analogues during childhood [12]. Data relating to the appropriateness of this therapy in individual patients were not available. In addition, $68 \%$ of these patients were receiving analgesics at baseline, and $22 \%$ were taking opioids [12]. In a web-based survey of 150 adults with XLH (information on sex was not reported), 65\% $(n=97)$ reported at least one orthopaedic surgery, including osteotomy (63\%), knee replacement (12\%) and hip replacement (8\%) in their medical history [14]. Current phosphate/vitamin D therapy was reported by $62 \%$ of the individuals in the study [14].

\section{Clinical management and awareness of XLH in adults}

Several publications that included information relating to clinical management indicated that many adults with XLH stop receiving treatment and may not be followed up after childhood $[2,3,14,53]$. For example, in a survey of 150 adults with XLH published in $2015,38 \%$ of the respondents were not receiving phosphate/vitamin $\mathrm{D}$ at the time of participation in the study, despite $97 \%$ of all respondents reporting bone or joint pain [14]. Limited information on the level of awareness of XLH in adults among clinicians was reported in the literature; however, this emerged as a key theme highlighted by numerous authors of publications included in the systematic review [33, 54-61].

Complications associated with conventional supplementation therapy were reported inconsistently, although hyperpara- 


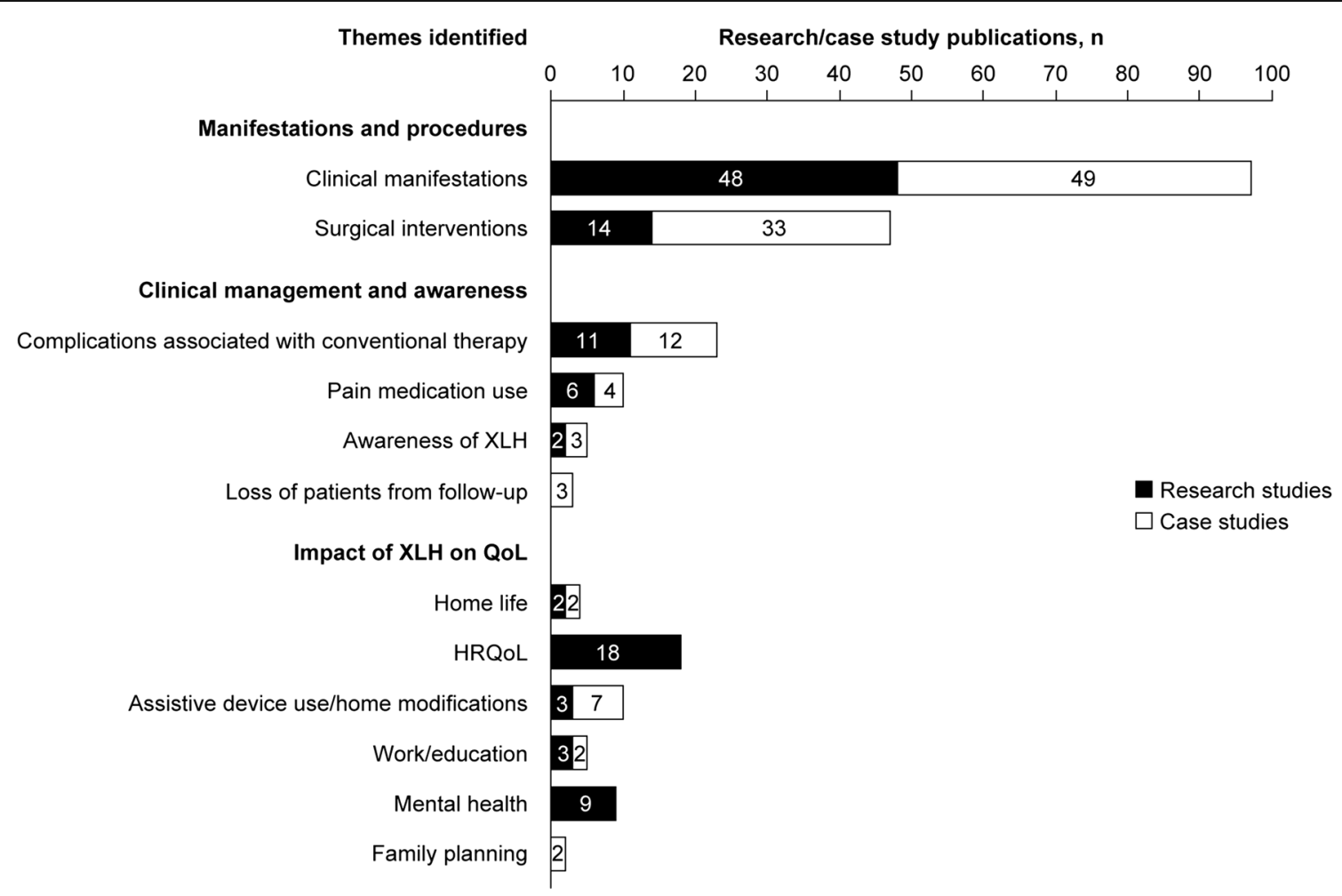

Fig. 2 Number of research and case study publications $(n=112)$ that include specific aspects of XLH in adulthood. Research study articles/ conference abstracts $(n=59)$ and case study articles/conference abstracts

thyroidism and nephrocalcinosis were described in several publications (Fig. 2) [14, 23, 29, 38, 62-71]. In one example, out of 150 adults with XLH who responded to a web-based survey, hyperparathyroidism and nephrocalcinosis were reported by $33 \%$ and $25 \%$, respectively [14]. All of the individuals who reported these conditions were receiving phosphate/ vitamin D at the time of the survey [14]. Data on how complications were managed were also sparse. However, six cases of parathyroidectomy being recommended following the development of tertiary hyperparathyroidism were documented in the case studies $[53,62,63,65,69,70]$.

Prescription pain medication use by adults with XLH was documented in two research studies, in which approximately $70 \%$ of participants were receiving pain medication of some type and 18 to $22 \%$ of all participants were taking opioids (Table 1) [12-14]. The use and effectiveness of supportive treatment measures such as physiotherapy, occupational therapy and exercise interventions were not consistently reported.

\section{Impact of XLH on quality of life}

\section{Impact on $\mathrm{HRQ}$ oL and pain}

HRQoL and/or pain in adults with XLH, as assessed using validated instruments, were reported in 14 publications describing eight distinct studies (Table 2). These data $(n=53)$ were included in this analysis. HRQoL, health-related quality of life; QoL, quality of life; XLH, X-linked hypophosphataemia

demonstrated that XLH had a substantial and wide-ranging negative impact on HRQoL in adulthood, particularly relating to physical function and pain. For example, baseline scores relating to physical aspects of the 36-item Short-Form Health Survey (SF-36) and the Western Ontario and McMaster Universities Osteoarthritis Index (WOMAC) indicated poor HRQoL in 28 adults with XLH participating in a clinical trial [76]. In a larger, phase 3 clinical trial, $72 \%$ of 134 participants reported Brief Pain Inventory (BPI) worst pain scores of higher than 6.0, indicating severe pain [12]. Furthermore, a study of 24 adults with XLH reported more severe impairment in every domain of the 5-level EuroQol 5-dimension (EQ-5D$5 \mathrm{~L})$ questionnaire relative to normative data [11]. In that publication, mobility problems were recorded by $88 \%$ of participants compared with $26 \%$ of the general population; pain and discomfort were recorded by $92 \%$ of participants compared with $42 \%$ of the general population sample. When these individuals with XLH were compared with adults with osteogenesis imperfecta $(n=43)$ or fibrous dysplasia $(n=42)$, overall HRQoL was found to be similar across all three groups, with adults with XLH more likely to have experienced problems with mobility, self-care and usual activity than those with the other conditions [11].

HRQoL among adults with XLH $(n=52)$ participating in a paired cohort study was significantly worse than that of agematched adults with axial spondyloarthritis $(n=52)$, a chronic 


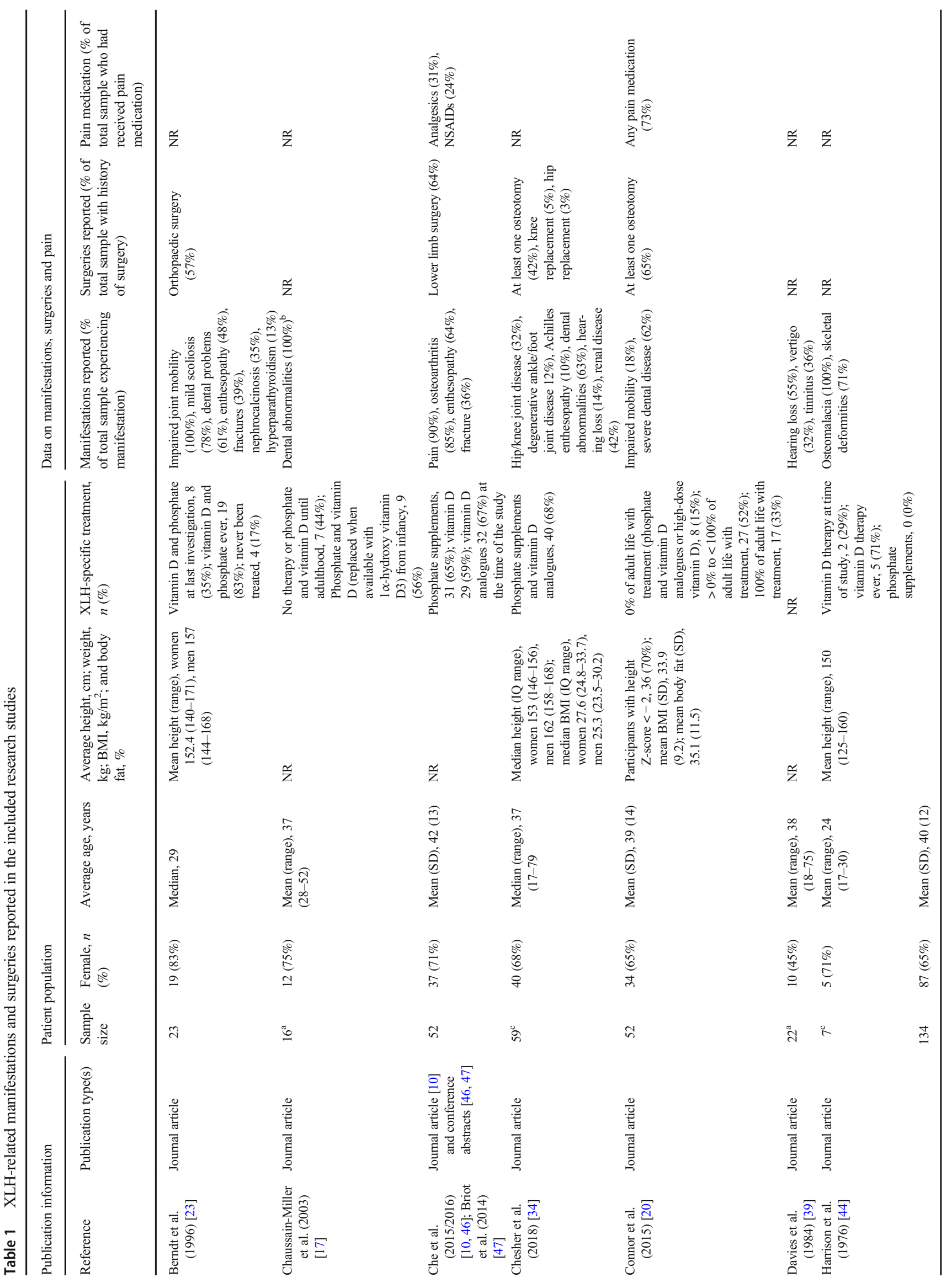




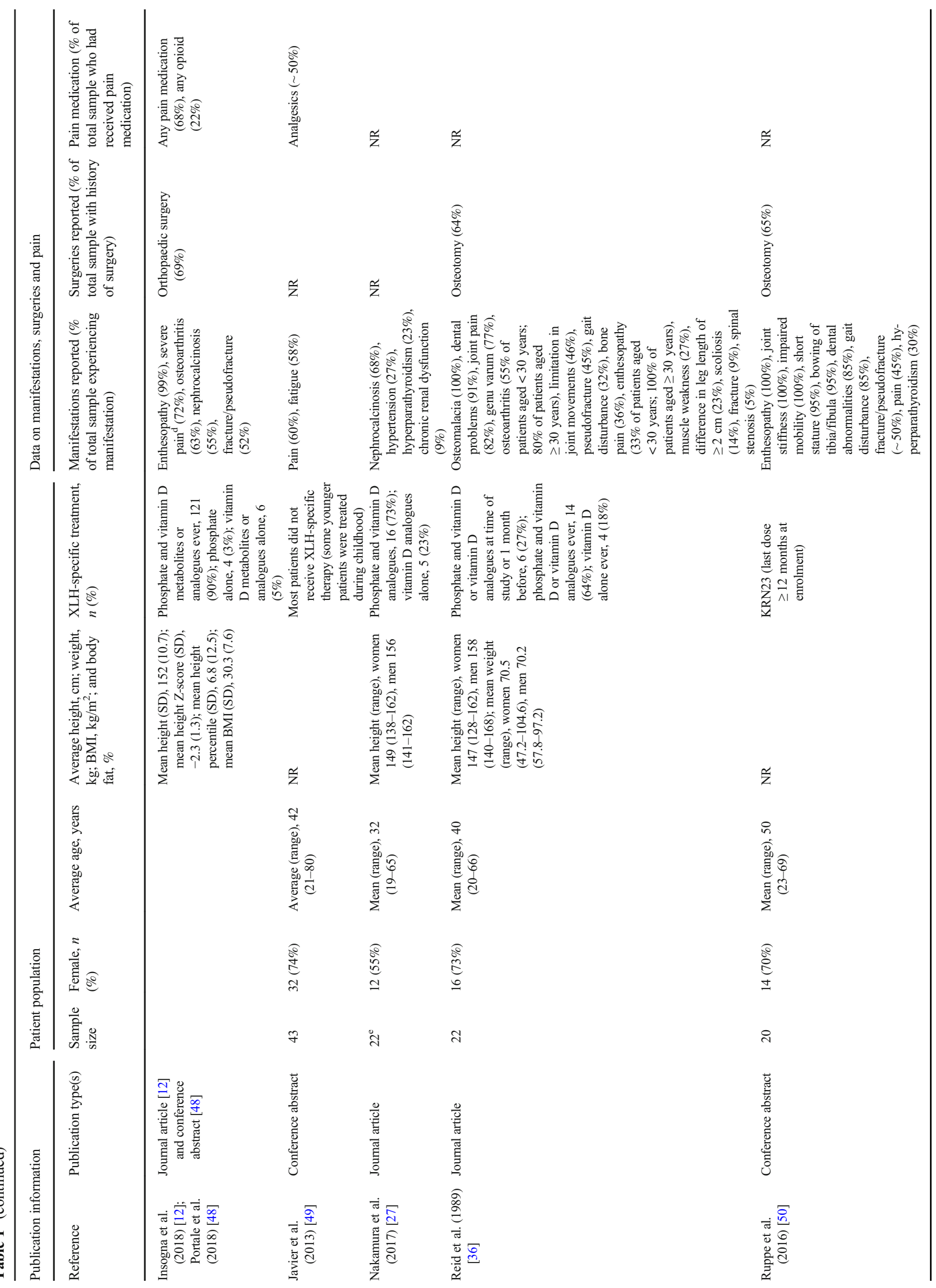




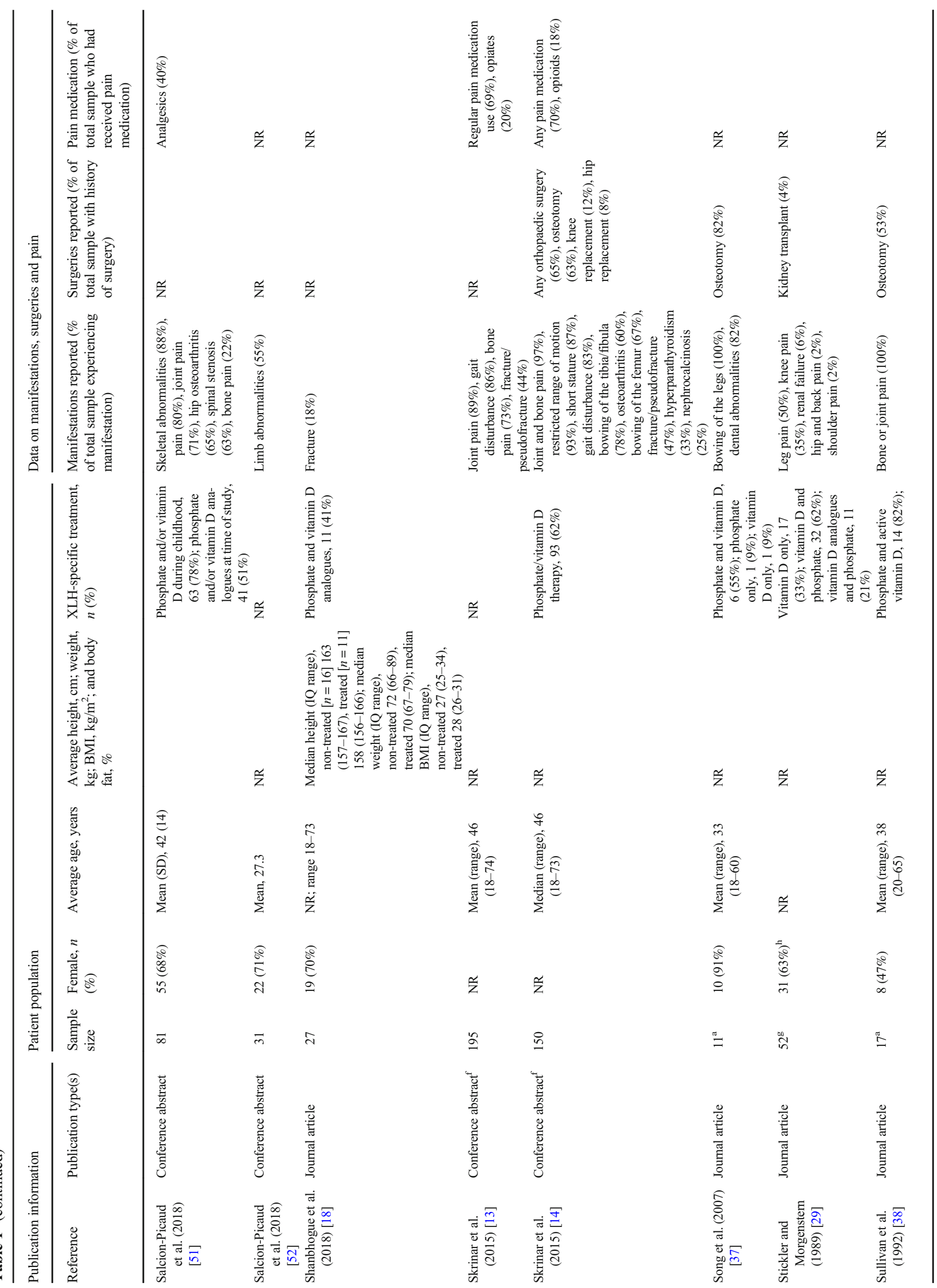




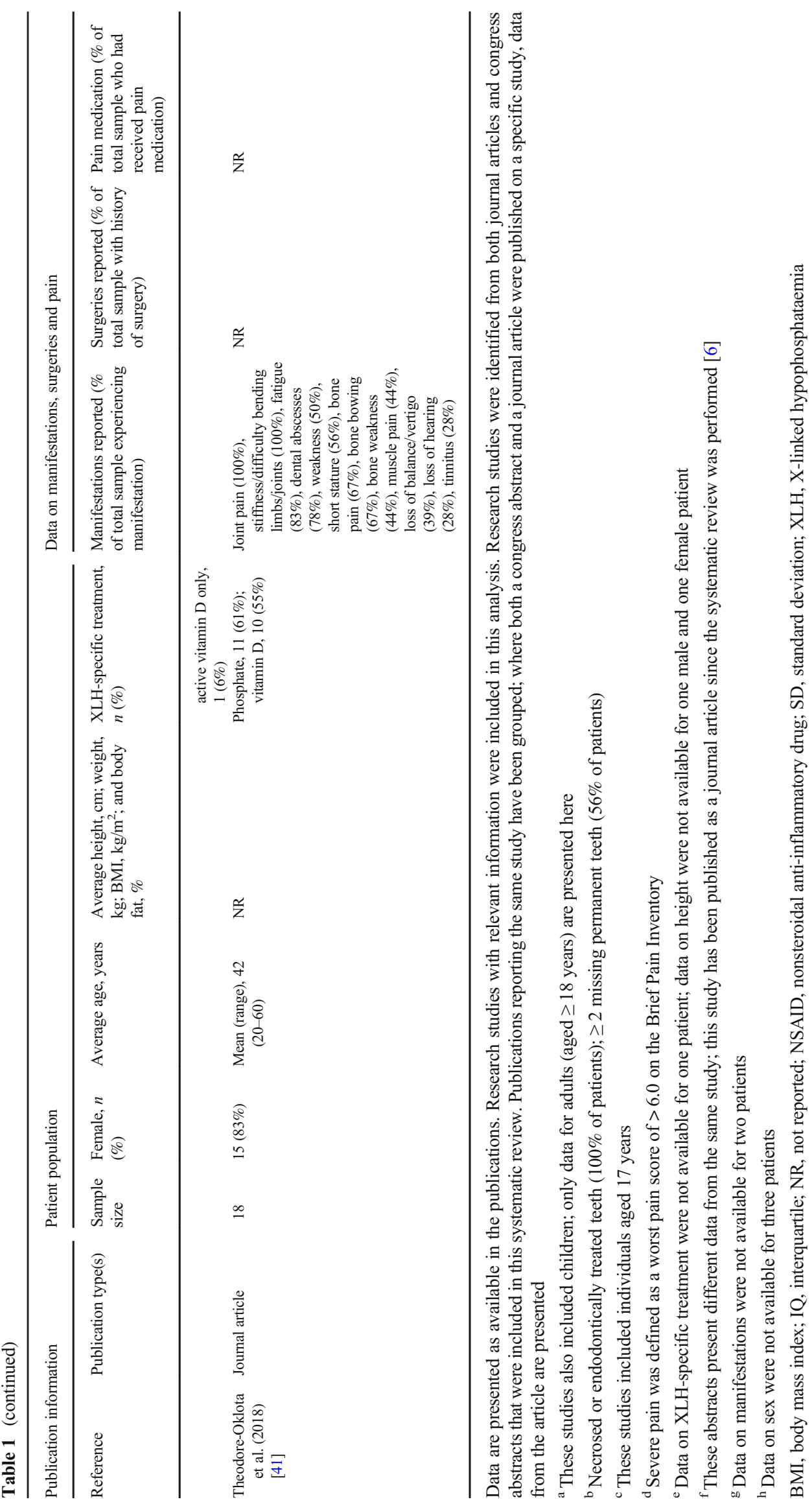




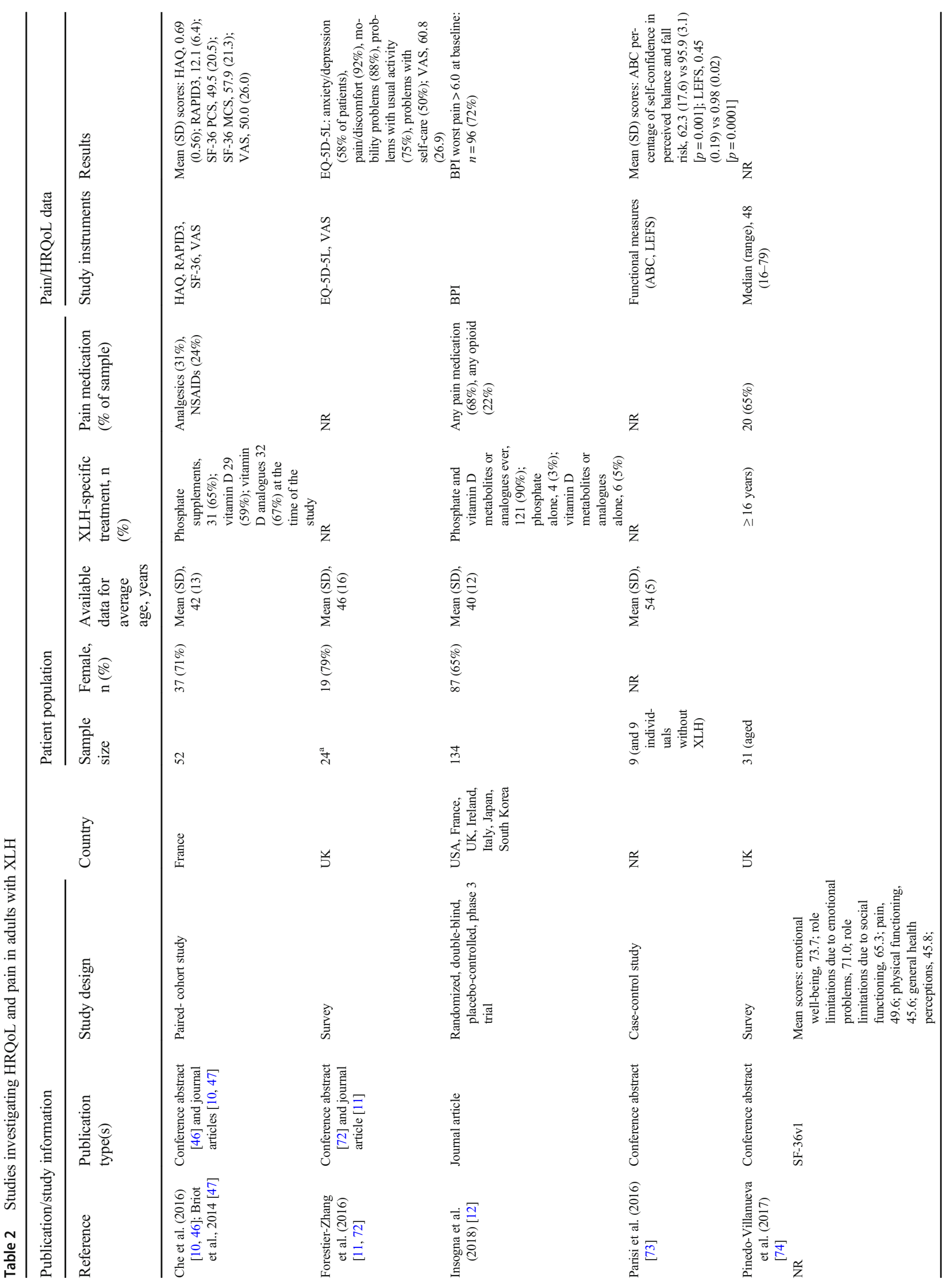




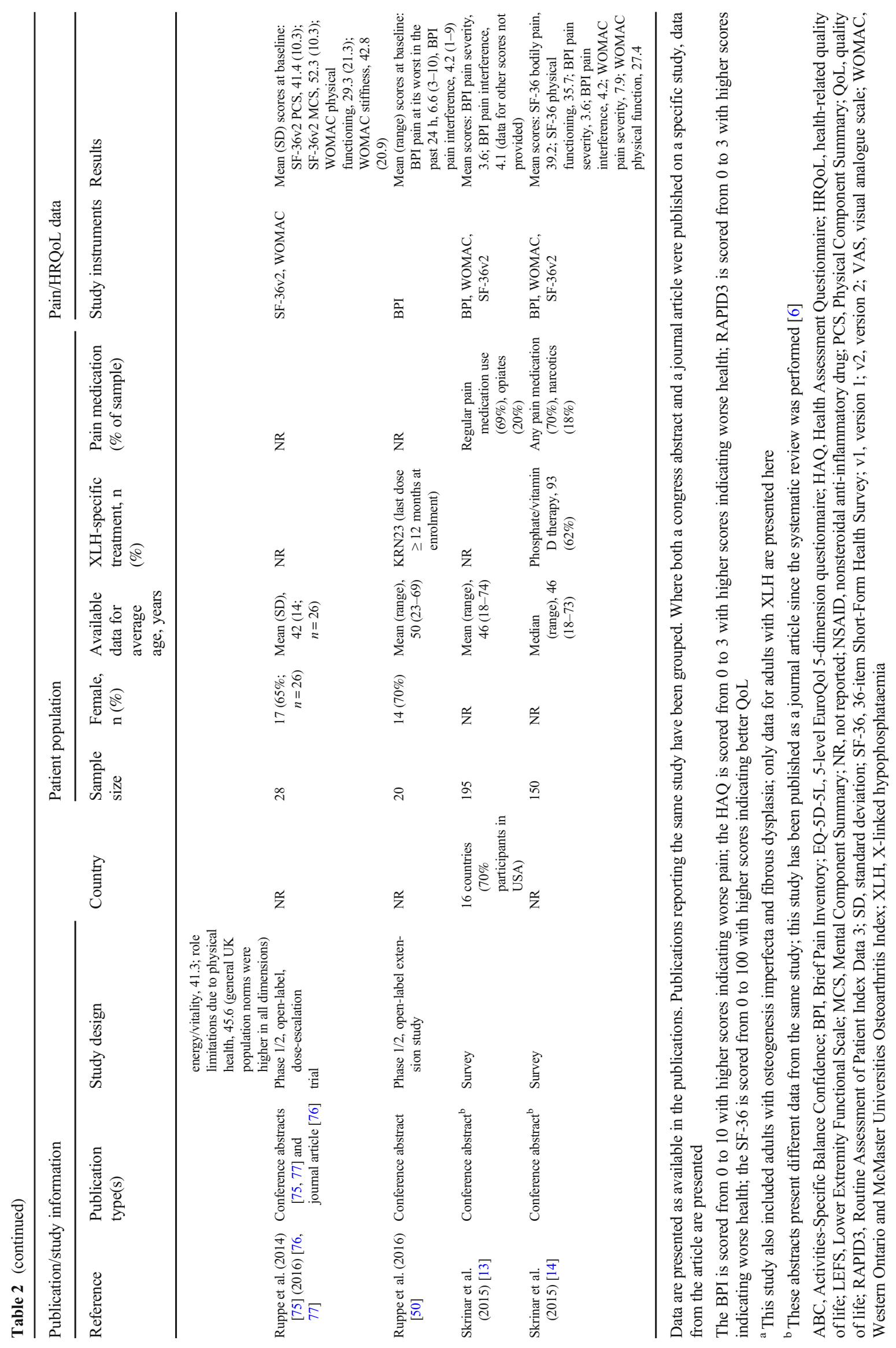


rheumatological condition known to substantially reduce HRQoL [10]. Specifically, average scores on the visual analogue scale (VAS) for pain, the Physical Component Summary (PCS) of the SF-36 and the Routine Assessment of Patient Index Data 3 (RAPID3) reflected significantly poorer HRQoL among participants with XLH than those with axial spondyloarthritis (VAS pain, 50.0 vs 36.0; SF-36 PCS, 49.5 vs 58.3; RAPID3, 12.1 vs 8.9 for patients with XLH and axial spondyloarthritis, respectively; all $p<0.05$ ). Health Assessment Questionnaire (HAQ) scores, which relate to functional disability and pain in rheumatic diseases, were similar in both groups of patients. For the adults with XLH in the study, HRQoL was found to deteriorate with increasing age [10]. Treatment with phosphate and vitamin D was significantly associated with better mental health, as measured by the Mental Component Summary of the SF-36, although not with other aspects of HRQoL [10].

\section{Impact on home life and work}

A negative impact of XLH on the home and work lives of adults with the disease was noted in several publications [13, 23, 24, 41, 50, 60, 78-81]. In interviews with 18 adults with XLH about their symptoms and functional limitations, participants reported that the condition had an impact on their work $(n=14)$ and housework $(n=12)$, as well as their ability to get dressed $(n=10)$, go shopping $(n=10)$, do laundry $(n=10)$ and other activities of daily living [41]. Additionally, several studies recorded the use of assistive devices for mobility among adults with XLH and/or highlighted a need for home modifications [13, 29, 41, 56, 78-82]. There was limited information available on the psychological impact of living with XLH or how the disease and its associated limitations affect partnership and family life. In the interviews with adults with XLH, two-thirds of the 18 participants reported feelings of sadness or depression [41].

Inability to work was found to be associated with both dental and psychosocial problems in a retrospective study of 23 adults with XLH [23]. Another study noted that unemployment and early retirement were more frequent among adults with XLH than in the general population [24]. None of the studies investigated the frequency with which adults with XLH need to take time off work as a consequence of the disease. Limited direct evidence was available regarding the financial burden of $\mathrm{XLH}$ on individuals. However, a cross-sectional study on dental health that included 36 adults with XLH in Denmark (rated as good quality) suggested that the high level of dental care received by adults with XLH represents a substantial economic burden carried by patients [19].

\section{Evidence from the structured Internet search}

A total of 19 web-based sources were identified from the structured Internet search (Supplementary Fig. S2), covering a wide range of topics including clinical manifestations and procedures, lack of disease awareness, complications associated with conventional supplementation therapy, family planning and financial pressure (Supplementary Table S4). These sources were distinct from those in the scientific literature as they contained testimonials from adults who had XLH themselves, as well as additional details from studies identified in the systematic review. For example, a congress poster describing results from a web-based survey included additional analyses to those presented in the published abstract $[14,83]$. The poster reported that in 165 adults with XLH (median age [range], 45 [18-46, 48, 50, 53-71, 76, 78-84] years), average scores on the WOMAC were higher for pain (39.4 vs 14.1), stiffness (50.2 vs 20.1) and physical functioning (40.9 vs 15.4) than those reported in the general population, indicating poorer HRQoL [83]. Use of a walking device was reported by $32 \%$ of these individuals.

\section{Discussion}

XLH in adults has received little attention, owing to the rarity of the disease and a clinical focus on management of the condition in children $[2,3]$. This systematic review collated evidence relating to the burden of XLH in adulthood, demonstrating substantial unmet need. Data show that adults with XLH experience a spectrum of clinical manifestations that impair physical function, cause pain and reduce HRQoL [6, $10-12,14,36,41,76]$. Consequently, these individuals frequently suffer a high burden of disease that has an impact on their home and work lives [23, 24, 41]. Despite this, many adults with XLH do not receive appropriate therapy, including symptomatic and supportive measures as well as conventional supplementation with phosphate and active vitamin $\mathrm{D}[2,3$, 8]. A plausible hypothesis is that this may indicate a lack of awareness among healthcare professionals and/or young adults with XLH of the need for ongoing specialist care and treatment in adulthood.

Data collated in the systematic review demonstrate the diversity of manifestations associated with XLH in adulthood, as well as the lifelong and progressive nature of the disease. Owing to abnormalities in childhood skeletal development, adults with XLH tend to be short and may have skeletal deformities and gait abnormalities [14, 36, 41, 50], with osteoarthritis developing as a consequence of both disease-specific metabolic alteration and long-term weight bearing on misaligned joints [6]. Pain, dental problems and hearing loss are reported with higher frequency in adults than in children $[6,36]$. In addition, adults with XLH experience manifestations associated with 
chronic hypophosphataemia and ongoing osteomalacia that are not typically reported in children $[4,6,36]$; these include fractures and pseudofractures, extraosseous calcifications, stiffness and impaired mobility [10, 12, 14, 36, 50]. Together, these manifestations contribute to a substantial burden of disease in adults with XLH.

The physical and psychological challenges of living with XLH extend beyond the direct effects of these clinical manifestations. Factors such as limited mobility, chronic pain and fatigue may have far-reaching consequences on mental wellbeing considering how they are likely to affect participation in sports and leisure activities [84]. This may also explain why people with XLH are often overweight, as suggested by the reports of mean or median BMI over $25 \mathrm{~kg} / \mathrm{m}^{2}$ [18, 20, 34, 48]. Furthermore, the psychological burden of living with a disorder that affects physical appearance should be considered. Thus, it is important to ensure continuous healthcare for adults with XLH from a coordinated multidisciplinary team, including physical therapy and mental health support where appropriate [8]. There are currently insufficient data in the medical literature on how to quantify and monitor functional deficits in adults with XLH, and the associated impacts on home and work lives. Considering the significant impact of physical ability on perceived quality of life, development of standards for assessing these aspects in adults with XLH is crucial. Such standards would enable clinicians to evaluate individual patient needs, inform treatment strategies and support longitudinal monitoring of disease progression and treatment outcomes.

The level of healthcare resource utilization among adults with XLH, including high frequencies of medical complications, surgical interventions and prescription medication usage $[6,12,14]$, is indicative of significant economic burden. However, research is needed to establish the true economic impact on the healthcare system, society and the individual. In addition, robust long-term observational studies are needed to extend our understanding of the evolution of disease burden over an individual's lifetime and identify potential risk factors for declining physical function. To build on the growing HRQoL evidence base, future clinical trials in adults with XLH should include appropriate patient-reported outcome measures as endpoints. Further research characterizing the wide-ranging effects of the disease from the patient perspective, including the support received from families, friends, employers and wider society, will provide a comprehensive picture of the impact of XLH on the lives of adults with the condition. Research focusing on the clinical management and awareness of XLH in adults is also warranted. This should include studies to evaluate the impact and potential shortcomings of specific treatment strategies and studies to determine optimal assessments for measuring physical performance and disease burden in clinical practice.

The findings from this systematic review provide insights into the unmet needs associated with XLH in adulthood; however, several limitations should be considered, including the generally low quality of available evidence. Notably, although there have been very few clinical trials conducted in adults with this rare disease, the evidence from two-thirds of the non-randomized study publications included in this review was rated as satisfactory or good in the formal quality assessment performed. While case study publications are often narrow in scope, with few documenting comprehensive medical histories, these publications provided a rich source of qualitative information highlighting the broad nature of symptoms that adults with XLH experience. In addition, insights captured from narrative reviews, which are not typically included in systematic reviews, were considered important in this study given the rarity of XLH and the lack of data on aspects such as disease awareness. Other limitations include the heterogeneity of available data, in terms of study design and patient demographics, and the range of terminology used to describe symptoms, treatments and procedures, both of which preclude direct comparisons being made across different studies. Despite these limitations, this review provides a comprehensive summary of current evidence on the unmet needs of adults with XLH.

Data captured in this systematic review highlight that XLH in adulthood is associated with considerable disease burden and diminished quality of life, with individuals often experiencing severe pain, early onset osteoarthritis and progressive disability. There are key areas of unmet need and further research is needed to quantify the associated socioeconomic burden of XLH in adults and improve the multidisciplinary management of XLH in adults. It is plausible that the apparent lack of awareness among healthcare professionals and patients themselves of the need for ongoing disease management in adulthood contributes to the burden of disease. Increasing understanding of the impact of XLH in adulthood may facilitate continuity of multidisciplinary care for individuals as they transition from paediatric to adult services, and thereby improve outcomes.

Author contributions All authors contributed to the study design, interpretation of data and critical revision of the manuscript for important intellectual content. All authors approved the final version of the manuscript for submission.

Funding information Medical writing support and assistance with the systematic review were provided by Dr. Emily Stock and Dr. Sarah Graham of PharmaGenesis London, UK, and funded by Kyowa Kirin International.

Data availability Data sharing requirements are not applicable to this article as the data were synthesized from previously published reports.

\section{Compliance with ethical standards}

As this was secondary research, no ethics approval or patient consent was required. 
Guarantor Lothar Seefried.

Conflict of interest P. Harvengt is a member of RVRH-XLH (a member of the International XLH Alliance), which has received funding from Kyowa Kirin for the organization of educational events, and has provided unpaid consulting services to Kyowa Kirin. P. Harvengt is employed by GSK. This publication was prepared by P. Harvengt in his personal capacity. M. Smyth is a former employee of Kyowa Kirin. R. Keen has received honorarium and consultancy fees from Kyowa Kirin. L. Seefried has received honoraria for lectures and advice from Kyowa Kirin.

Open Access This article is licensed under a Creative Commons Attribution-NonCommercial 4.0 International License, which permits any non-commercial use, sharing, adaptation, distribution and reproduction in any medium or format, as long as you give appropriate credit to the original author(s) and the source, provide a link to the Creative Commons licence, and indicate if changes were made. The images or other third party material in this article are included in the article's Creative Commons licence, unless indicated otherwise in a credit line to the material. If material is not included in the article's Creative Commons licence and your intended use is not permitted by statutory regulation or exceeds the permitted use, you will need to obtain permission directly from the copyright holder. To view a copy of this licence, visit http://creativecommons.org/licenses/by-nc/4.0/.

\section{References}

1. Orphanet (2019) X-linked hypophosphatemia. https://www.orpha. net/consor/cgi-bin/OC_Exp.php?Expert=89936. Accessed August 2019

2. Carpenter TO, Imel EA, Holm IA, Jan de Beur SM, Insogna KL (2011) A clinician's guide to X-linked hypophosphatemia. J Bone Miner Res 26(7):1381-1388

3. Linglart A, Biosse-Duplan M, Briot K, Chaussain C, Esterle L, Guillaume-Czitrom S, Kamenicky P, Nevoux J, Prie D, Rothenbuhler A, Wicart P, Harvengt P (2014) Therapeutic management of hypophosphatemic rickets from infancy to adulthood. Endocr Connect 3(1):R13-R30

4. Beck-Nielsen SS, Mughal Z, Haffner D, Nilsson O, Levtchenko E, Ariceta G, de Lucas CC, Schnabel D, Jandhyala R, Mäkitie O (2019) FGF23 and its role in X-linked hypophosphatemia-related morbidity. Orphanet J Rare Dis 14(1):58

5. McWhorter AG, Seale NS (1991) Prevalence of dental abscess in a population of children with vitamin D-resistant rickets. Pediatr Dent 13(2):91-96

6. Skrinar A, Dvorak-Ewell M, Evins A, Macica C, Linglart A, Imel EA, Theodore-Oklota C, San Martin J (2019) The lifelong impact of X-linked hypophosphatemia: results from a burden of disease survey. J Endocr Soc 3(7):1321-1334

7. EMA (2019) Crysvita: summary of product characteristics. https:// www.ema.europa.eu/en/documents/product-information/crysvitaepar-product-information_en.pdf. Accessed August 2019

8. Haffner D, Emma F, Eastwood DM, Duplan MB, Bacchetta J, Schnabel D, Wicart P, Bockenhauer D, Santos F, Levtchenko E, Harvengt P, Kirchhoff M, Di Rocco F, Chaussain C, Brandi ML, Savendahl L, Briot K, Kamenicky P, Rejnmark L, Linglart A (2019) Clinical practice recommendations for the diagnosis and management of X-linked hypophosphataemia. Nat Rev Nephrol 15(7):435-455

9. FDA (2018) Crysvita: prescribing information. https://www. accessdata.fda.gov/drugsatfda_docs/label/2019/761068s004lbl. pdf. Accessed May 2020
10. Che H, Roux C, Etcheto A, Rothenbuhler A, Kamenicky P, Linglart A, Briot K (2016) Impaired quality of life in adults with X-linked hypophosphatemia and skeletal symptoms. Eur J Endocrinol 174(3):325-333

11. Forestier-Zhang L, Watts L, Turner A, Teare H, Kaye J, Barrett J, Cooper C, Eastell R, Wordsworth P, Javaid MK, PinedoVillanueva R (2016) Health-related quality of life and a costutility simulation of adults in the UK with osteogenesis imperfecta, $\mathrm{X}$-linked hypophosphatemia and fibrous dysplasia. Orphanet J Rare Dis 11(1):1-9

12. Insogna K, Briot K, Imel E, Kamenicky P, Ruppe M, Portale A, Weber T, Pitukcheewanont P, Cheong H, Jan de Beur S, Imanishi Y, Ito N, Lachmann R, Tanaka H, Perwad F, Zhang L, Chen C, Theodore-Oklota C, Mealiffe M, San Martin J, Carpenter T (2018) A randomized, double-blind, placebo-controlled, phase 3 trial evaluating the efficacy of burosumab, an anti-FGF23 antibody, in adults with X-linked hypophosphatemia: week 24 primary analysis. J Bone Miner Res 33(8):1383-1393

13. Skrinar A, Marshall A, San Martin J, Dvorak-Ewell M, MaCica C (2015) Pain resulting from unresolved skeletal disease has a significant impact on the daily function of adults with X-linked hypophosphatemia (XLH). J Bone Miner Res 30(Suppl 1):S457

14. Skrinar A, Ayla M, Javier San M, Melita D-E (2015) X-linked hypophosphatemia (XLH) impairs skeletal health outcomes and physical function in affected adults. Endocrine Society Annual Meeting, San Diego, CA, USA PP29-3

15. Moher D, Liberati A, Tetzlaff J, Altman DG (2009) Preferred reporting items for systematic reviews and meta-analyses: the PRISMA statement. PLoS Med 6(7):e1000097

16. Wells GA, Shea B, O'Connell D, Peterson J, Welch V, Losos M, Tugwell P (2019) The Newcastle-Ottawa Scale (NOS) for assessing the quality of nonrandomised studies in meta-analyses. http://www. ohri.ca/programs/clinical_epidemiology/oxford.asp. Accessed May 2020

17. Chaussain-Miller C, Sinding C, Wolikow M, Lasfargues JJ, Godeau G, Garabedian M (2003) Dental abnormalities in patients with familial hypophosphatemic vitamin D-resistant rickets: prevention by early treatment with 1-hydroxyvitamin D. J Pediatr 142(3):324-331

18. Shanbhogue VV, Hansen S, Jorgensen NR, Beck-Nielsen SS (2018) Impact of conventional medical therapy on bone mineral density and bone turnover in adult patients with X-linked hypophosphatemia: a 6-year prospective cohort study. Calcif Tissue Int 102(3):321-328

19. Andersen MG, Beck-Nielsen SS, Haubek D, Hintze H, Gjorup H, Poulsen S (2012) Periapical and endodontic status of permanent teeth in patients with hypophosphatemic rickets. J Oral Rehabil 39(2):144-150

20. Connor J, Olear EA, Insogna KL, Katz L, Baker S, Kaur R, Simpson CA, Sterpka J, Dubrow R, Zhang JH, Carpenter TO (2015) Conventional therapy in adults with X-linked hypophosphatemia: effects on enthesopathy and dental disease. J Clin Endocrinol Metab 100(10):3625-3632

21. Veilleux LN, Cheung M, Ben Amor M, Rauch F (2012) Abnormalities in muscle density and muscle function in hypophosphatemic rickets. J Clin Endocrinol Metab 97(8): E1492-E1498

22. Veilleux LN, Cheung MS, Glorieux FH, Rauch F (2013) The muscle-bone relationship in X-linked hypophosphatemic rickets. J Clin Endocrinol Metab 98(5):E990-E995

23. Berndt M, Ehrich JHH, Lazovic D, Zimmermann J, Hillmann G, Kayser C, Prokop M, Schirg E, Siegert B, Wolff G, Brodehl J (1996) Clinical course of hypophosphatemic rickets in 23 adults. Clin Nephrol 45(1):33-41

24. Ehrich JHH, Filler G (1996) Hypophosphataemic rickets in children and adults. Nephrol Dial Transplant 11(9):1918-1919 
25. Haffner D, Weinfurth A, Manz F, Schmidt H, Bremer HJ, Mehls O, Scharer K (1999) Long-term outcome of paediatric patients with hereditary tubular disorders. Nephron 83(3):250-260

26. Lee SH, Agashe MV, Suh SW, Yoon YC, Song SH, Yang JH, Lee H, Song HR (2012) Paravertebral ligament ossification in vitamin D-resistant rickets: incidence, clinical significance, and genetic evaluation. Spine 37(13):E792-E796

27. Nakamura Y, Takagi M, Takeda R, Miyai K, Hasegawa Y (2017) Hypertension is a characteristic complication of X-linked hypophosphatemia. Endocr J 64(3):283-289

28. Nehgme R, Fahey JT, Smith C, Carpenter TO (1997) Cardiovascular abnormalities in patients with $\mathrm{X}$-linked hypophosphatemia. J Clin Endocrinol Metab 82(8):2450-2454

29. Stickler GB, Morgenstern BZ (1989) Hypophosphataemic rickets: final height and clinical symptoms in adults. Lancet 2(8668):902905

30. Zhang C, Zhao Z, Sun Y, Xu L, JiaJue R, Cui L, Pang Q, Jiang Y, Li M, Wang O, He X, He S, Nie M, Xing X, Meng X, Zhou X, Yan L, Kaplan JM, Insogna KL, Xia W (2019) Clinical and genetic analysis in a large Chinese cohort of patients with X-linked hypophosphatemia. Bone 121:212-220

31. Biosse Duplan M, Coyac BR, Bardet C, Zadikian C, Rothenbuhler A, Kamenicky P, Briot K, Linglart A, Chaussain C (2017) Phosphate and vitamin D prevent periodontitis in X-linked hypophosphatemia. J Dent Res 96(4):388-395

32. Beck-Nielsen SS, Brusgaard K, Rasmussen LM, Brixen K, BrockJacobsen B, Poulsen MR, Vestergaard P, Ralston SH, Albagha OM, Poulsen S, Haubek D, Gjorup H, Hintze H, Andersen MG, Heickendorff L, Hjelmborg J, Gram J (2010) Phenotype presentation of hypophosphatemic rickets in adults. Calcif Tissue Int 87(2): 108-119

33. Econs MJ, Samsa GP, Monger M, Drezner MK, Feussner JR (1994) X-linked hypophosphatemic rickets: a disease often unknown to affected patients. Bone Miner 24(1):17-24

34. Chesher D, Oddy M, Darbar U, Sayal P, Casey A, Ryan A, Sechi A, Simister C, Waters A, Wedatilake Y, Lachmann RH, Murphy E (2018) Outcome of adult patients with X-linked hypophosphatemia caused by PHEX gene mutations. J Inherit Metab Dis 41(5):865876

35. McNair SL, Stickler GB (1969) Growth in familial hypophosphatemic vitamin-D-resistant rickets. N Engl J Med 281(10):512-516

36. Reid IR, Hardy DC, Murphy WA, Teitelbaum SL, Bergfeld MA, Whyte MP (1989) X-linked hypophosphatemia: a clinical, biochemical and histopathologic assessment of morbidity in adults. Medicine 68(6):336-352

37. Song HR, Park JW, Cho DY, Jae HY, Yoon HR, Jung SC (2007) PHEX gene mutations and genotype-phenotype analysis of Korean patients with hypophosphatemic rickets. J Korean Med Sci 22(6): 981-986

38. Sullivan W, Carpenter T, Glorieux F, Travers R, Insogna K (1992) A prospective trial of phosphate and 1,25-dihydroxyvitamin D3 therapy in symptomatic adults with X-linked hypophosphatemic rickets. J Clin Endocrinol Metab 75(3):879-885

39. Davies M, Kane R, Valentine J (1984) Impaired hearing in X-linked hypophosphataemic (vitamin-D-resistant) osteomalacia. Ann Intern Med 100(2):230-232

40. Endo I, Fukumoto S, Ozono K, Namba N, Inoue D, Okazaki R, Yamauchi M, Sugimoto T, Minagawa M, Michigami T, Nagai M, Matsumoto T (2015) Nationwide survey of fibroblast growth factor 23 (FGF23)-related hypophosphatemic diseases in Japan: prevalence, biochemical data and treatment. Endocr J 62(9):811-816

41. Theodore-Oklota C, Bonner N, Spencer H, Arbuckle R, Chen CY, Skrinar A (2018) Qualitative research to explore the patient experience of X-linked hypophosphatemia and evaluate the suitability of the BPI-SF and WOMAC as clinical trial end points. Value Health 21(8):973-983

42. Wiemann S, Frenzel Baudisch N, Jordan RA, Kleinheinz J, Hanisch M (2018) Oral symptoms and oral health-related quality of life in people with rare diseases in Germany: a cross-sectional study. Int J Environ Res Public Health 15(7)

43. Yuan L, Wu S, Xu H, Xiao J, Yang Z, Xia H, Liu A, Hu P, Lu A, Chen Y, Xu F, Deng H (2015) Identification of a novel PHEX mutation in a Chinese family with $\mathrm{X}$-linked hypophosphatemic rickets using exome sequencing. Biol Chem 396(1):27-33

44. Harrison JE, Cumming WA, Fornasier V, Fraser D, Kooh SW, McNeill KG (1976) Increased bone mineral content in young adults with familial hypophosphatemic vitamin D refractory rickets. Metabolism 25(1):33-40

45. Javaid M, Delmestri A, Shaw N, Prieto-Alhambra D, Cooper C, Pinedo-Villanueva R (2018) X-linked hypophosphatemia: burden of disease using United Kingdom primary care data. JBMR Plus 2(Suppl 1):S14-S15

46. Che H, Roux C, Etcheto A, Rothenbuhler A, Kamenicky P, Linglart A, Briot K (2015) Quality of life of adults with X-linked hypophosphatemic rickets. European Congress of rheumatology, Rome, Italy THU0551

47. Briot K, Che H, Etcheto A, Rothenbuhler A, Kamenicky P, Linglart A, Roux C (2014) Quality of life assessment of adult patients with X-linked hypophosphatemia. Arthritis Rheumatol 66(SUPPL. 10): S107-S108

48. Portale AA, Mealiffe M, San Martin J, Carpenter T, Insogna K, Imel E, Kamenicky P, Imanishi Y, Ito N, Perwad F, Zhang L, Theodore-Oklota C (2018) Burosumab improves phosphorus metabolism and fracture healing in adults with X-linked hypophosphatemia (XLH). Kidney Week, San Diego, CA, USA TH-OR023

49. Javier RM, Briot K, Cohen-Solal M, Cortet B, Eloy C, Laroche M, Lafforgue P, De Vernejoul MC (2013) X-linked hypophosphatemia in adults and rheumatological manifestations: cross-sectional survey of the bone section of the French Society of Rheumatology sfros. J Bone Miner Res 28(Suppl 1):S385

50. Ruppe M, Peacock M, Weber T, Portale A, Insogna K, Imel E, Luca D, Skrinar A, Mealiffe M, Martin JS, Carpenter T (2016) Clinical and radiographic characteristics of adult X-linked hypophosphatemia (XLH) in a cohort of patients treated with KRN23, an antibody to FGF23. J Bone Miner Res 31(Suppl 1): S393

51. Salcion-Picaud A, Lassalle L, Merzoug V, Usardi A, Rothenbuhler A, Kamenicky P, Roux C, Linglart A, Briot K (2018) High prevalence of enthesopathies in patients with X-linked hypophosphatemia. Ann Rheum Dis 77(Suppl 2):1046-1047

52. Salcion-Picaud A, Rothenbuhler A, Etcheto A, Molto A, Briot K, Linglart A (2018) Clinical and biological parameters associated to the severity of X-linked hypophosphatemia in children. European Society for Paediatric Endocrinology Annual Meeting, Athens, Greece P2-P041

53. Merzkani M, Bloom J, Bhaskaran M, Ali S (2016) X linked hypophosphatemic syndrome in a patient undergoing for renal transplant. Am J Kidney Dis 67(5):A5

54. Collins M (2018) Burosumab: at long last, an effective treatment for FGF23-associated hypophosphatemia. J Bone Miner Res 33(8): 1381-1382

55. Doess A, May M, Feig C, Keller I, Maessen D (2018) Real world evidence of hereditary hypophosphatemia in Germany - analysis of German SHI claims data for pediatric patients. Value Health 21(Suppl 3):S466

56. Lopez L, Ha D, Targovnik J, Shah B (2016) Looking beyond osteoporosis: diagnosing $\mathrm{X}$-linked hypophosphatemic rickets in a 60 year old female. American Association of Clinical Endocrinologists Annual Meeting, Orlando, FL, USA 619 
57. Maija M, Ingvars R (2015) X-linked hypophosphatemic rickets case report from Latvia. Endocrine Society Annual Meeting, San Diego, CA, USA FRI-217

58. Oheim R (2018) Realigning our thinking: XLH, a lifelong disease. Osteoporos Int 29(Suppl 1):S570

59. Ramirez B, Cook F, Mumm S, Gottesman G, Madson K, Whyte M (2016) Severe hypophosphatemia in adulthood associated with PHEX 3'-UTR mutation c.*231A $>$ G near the polyadenylation signal. J Bone Miner Res 31(Suppl 1):S287

60. Watts L, Wordsworth P (2015) Chiari malformation, syringomyelia and bulbar palsy in X-linked hypophosphataemia. BMJ Case Rep bcr2015211961

61. Arthur S, Chopra A (2011) Familial hypophosphatemia: an unusual presentation with low back ache, heel pain, and a limp in a young man, and literature review. Clin Rheumatol 30(4):585-589

62. Cheng A, Pelley EM (2016) Tertiary hyperparathyroidism caused by prolonged therapy of X-linked hypophosphatemic rickets. Endocr Rev 37(Suppl 1)

63. Crowley RK, Morrin M, Kilbane M, McKenna MJ (2010) Tertiary hyperparathyroidism associated with treatment of X-linked hypophosphataemia: paradoxical response to cinacalcet. Ir J Med Sci 179(Suppl 13):S534

64. Gupta S, Kilbane M, Vanderkamp S, McKenna MJ (2012) Osteosclerosis in congenital hypophosphatemic bone disorders. Endocr Rev 33

65. Kawano K, Yoshii K, Horiuchi K, Osawa M (2013) Cinacalcet has a limited effect in hyperparathyroidism secondary to X-linked hypophosphatemic rickets: a case report. Horm Res Paediatr 80(SUPPL. 1):380-381

66. Mitta S, Shibli-Rahhal A (2012) Cinacalcet use in X-linked hypophosphatemic rickets complicated by tertiary hyperparathyroidism and hypercalcemia. Endocr Rev 33(Suppl 1)

67. Sun GE, Suer O, Carpenter TO, Tan CD, Li-Ng M (2013) Heart failure in hypophosphatemic rickets: complications from high-dose phosphate therapy. Endocr Pract 19(1):e8-e11

68. Thomas N, Burnet R (2000) Hyperparathyroidism and cervical canal stenosis in twins with hypophosphatemic rickets. Pediatr Int 42(3):310-312

69. Tournis S, Georgoulas T, Zafeiris C, Papalexis C, Petraki K, Lyritis GP (2011) Tertiary hyperparathyroidism in a patient with X-linked hypophosphatemic rickets. J Musculoskelet Neuronal Interact 11(3):266-269

70. Vanacker A, Segaert M, Verbanck J, Van Dorpe J, Poppe B, Maes B (2008) Slow progression of chronic renal failure in a woman of short stature and leg deformities: what is the link? NDT Plus 1(4): 257-261

71. Yavropoulou MP, Kotsa K, Gotzamani Psarrakou A, Papazisi A, Tranga T, Ventis S, Yovos JG (2010) Cinacalcet in hyperparathyroidism secondary to $\mathrm{X}$-linked hypophosphatemic rickets: case report and brief literature review. Hormones 9(3):274-278

72. Forestier-Zhang L, Watts L, Turner A, Teare H, Barrett J, Wordsworth P, Kaye J, Javaid MK, Pinedo-Villanueva R (2016) Using the RUDY study platform to capture quality of life of adults with rare diseases of the bone. J Bone Miner Res 31(Suppl 1):S280
73. Parisi EJ, Feinn R, Ferraro S, Frey M, Garbalosa JC, Gonzalez R, Grgurich T, Muchemi F, Steigbigel K, Tommasini SM, Macica CM (2016) Significant impairments in joint mobility and range of function in adult patients with XLH. J Bone Miner Res 31(Suppl 1): S277

74. Pinedo-Villanueva R, Turner A, Barrett J, Cooper C, Javaid K (2017) Quality of life in adults with X-linked hypophosphataemia (XLH): preservation of emotional well-being despite significant limitations in physical domains. Osteoporos Int 28 Suppl 1:491

75. Ruppe $\mathrm{M}$, Zhang X, Imel E, Weber T, Klausner M, Ito T, Vergeire M, Humphrey J, Glorieux F, Portale A, Insogna K, Peacock M, Carpenter T (2014) Assessment of quality of life data after 4 monthly S.C. doses of a human monoclonal anti-fibroblast growth factor 23 antibody (KRN23) in adults with X-linked hypophosphatemia. Horm Res Paediatr 82(Suppl 1):80-81

76. Ruppe MD, Zhang X, Imel EA, Weber TJ, Klausner MA, Ito T, Vergeire M, Humphrey JS, Glorieux FH, Portale AA, Insogna K, Peacock M, Carpenter TO (2016) Effect of four monthly doses of a human monoclonal anti-FGF23 antibody (KRN23) on quality of life in X-linked hypophosphatemia. Bone Rep 5:158-162

77. Ruppe MD, Zhang X, Imel EA, Weber TJ, Klausner M, Ito T, Vergeire M, Humphrey J, Glorieux FH, Portale AA, Insogna K, Peacock M, Carpenter TO (2014) Effect of four monthly doses of a human monoclonal anti-FGF23 (fibroblast growth factor 23) antibody (KRN23) on quality of life in X-linked hypophosphatemia (XLH). Endocr Rev 35(Suppl 1)

78. Pekkarinen T, Lorenz-Depiereux B, Lohman M, Makitie O (2014) Unusually severe hypophosphatemic rickets caused by a novel and complex re-arrangement of the PHEX gene. Am J Med Genet A 164A(11):2931-2937

79. Yoshikawa S, Shiba M, Suzuki A (1968) Spinal-cord compression in untreated adult cases of vitamin-D resistant rickets. J Bone Joint Surg Am 50(4):743-752

80. Xie F, Cen ZD, Chen LL, Luo W (2014) Cervical spinal cord compression caused by X-linked hypophosphatemic rickets with a novel PHEX mutation. Neurol India 62(4):451-453

81. Do J, Kiser TS (2017) Inpatient rehabilitation for thoracic myelopathy caused by X-linked hypophosphatemia, a form of congenital rickets, after surgical decompression and fusion: a case report. PM R 9(Suppl 1):S197

82. Friberg B (2013) Brånemark system implants and rare disorders: a report of six cases. Int J Periodontics Restorative Dent 33:139-148

83. Skrinar A, Marshall A, San Martin J, Dvorak-Ewell M (2015) Xlinked hypophosphatemia (XLH) impairs skeletal health outcomes and physical function in affected adults [poster PP29-3]. Presented at the Endocrine Society Annual Meeting ENDO, 3-5 March 2015, San Diego, CA, USA

84. XLH Network, Inc. (2019) Voice of the patient report. https:// xlhnetwork.org/application/files/9415/7323/0655/VOP and Transcripts.pdf. Accessed Jan 2020

Publisher's note Springer Nature remains neutral with regard to jurisdictional claims in published maps and institutional affiliations. 